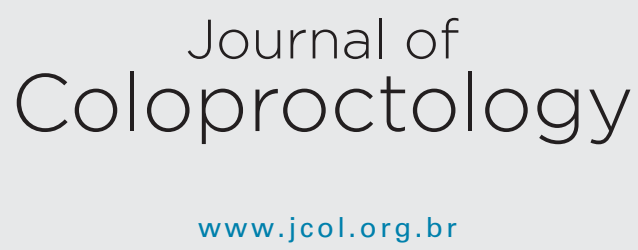

\title{
Editorial
}

\section{Extralevator abdominoperineal excision: a technique moving towards definitions and standardization}

\author{
Amputação abdominoperineal de reto extra-elevador: definições da \\ técnica e padronização
}

Over the past decades, management of rectal cancer patients witnessed great improvements regarding radiological staging, new forms of adjuvant therapy, advances in surgical technique and pathological reporting. Above it all, one of the most real advances is that rectal cancer is no longer a fatal disease as it was at the beginning of the 20th century.

Among the surgical developments, adoption of total mesorectal excision (TME) principles has yielded great dividends regarding decreased local recurrence rates and chances of cure. However, as worst outcomes were registered in low rectal tumours treated with abdominoperineal resection (APR) in comparison to anterior resection (AR), factors such as tumour biology, patterns of spread and technical issues were incriminated. In this setting, inadequacy of classical APR in achieving a free radial or circumferential margin was considered the main technical limitation. ${ }^{1}$

Subsequently, the technical proposition was introduced by Holms $^{2}$ to improve oncological results. Distinction with the classical APR (in which the levators are not removed with the specimen) was emphasized with the terms cylindrical, extended or extralevator APR (ELAPE). Removal of a cylindrical specimen aims to remove a greater amount of tissue from around the tumour, thus achieving a free circumferential resection margin (CRM).

Since then, indications of ELAPE have been discussed. Holm believed this was not an operation for every patient, and should be used for low ( $<1 \mathrm{~cm}$ from the dentate line) rectal cancer cases requiring a wider dissection due to threatening circumferential margin. ${ }^{3}$ Not less important, distinction of three or two ${ }^{4}$ forms of ELAPE in relation to the perineal dissection has also been a matter of debate, despite the general recognition that ELAPE is frequently accompanied by increased perineal morbidity either in lithotomy or prone positions. ${ }^{5}$ As rates of perineal wound complications are high (35-66\%) and related with radiotherapy, ${ }^{6}$ surgeons have tried to overcome this problem by using muscle graft (myocutaneous flaps), biological mesh fixation or even closure to prevent local hernias.

This vision of a selective indication aiming to reduce shortterm complications seems to be the preferred choice today, mainly for those patients at risk of intraoperative perforation, which raises local recurrence risks. ${ }^{7}$ Moreover, the decisionmaking process in an APR candidate is highly dependent on anatomical information derived from magnetic resonance imaging (MRI) either before or after nCRT. It has been proposed that RNM information is essential when considering alternative approaches. . $^{8}$

Although ELAPE is considered effective in reducing local recurrence, intraoperative tumour perforations and CRM positivity, $^{10}$ the reported oncological ${ }^{6,11,12}$ and morbidity outcomes ${ }^{13,14}$ compared to conventional APR are not uniform. This absence of difference might be due to a more radical performance of the so-called conventional APR or to pathological features of treated cases. For example, the presence of T2 or T4 anterior tumours treated with ELAPE in a certain series would not express an eventual superiority of this operative choice.

In the last JCOL number, the National Cancer Institute presents a retrospective series of ELAPE performed from 2003 to 2015, confronting fifty patients undergoing standard APEs against 22 ELAPE. ${ }^{15}$ All patients received nCRT and were operated in the prone position. According to the authors, ELAPE was indicated selectively in cases of sphincter complex or levator invasion, and a routine indication could not be established due to the increased perineal complications. 
Although an interesting work, the authors recognize some limitations such as the long study period (12 years) and different rates of surgical access among the groups. Certainly, those differences may lead to bias regarding comparative outcomes, mainly because the number of cases in each group was too different (67 vs. 22).

Despite this, one recognizes the better operative field provided by the better visualization during prone position. This choice is also associated with shorter operative times and less blood loss. ${ }^{6}$

Outcomes must be addressed in terms of oncological results and postoperative complications. In this manuscript, results were compared with an historical cohort of patients. However, there were some features that may have influenced results. Some of them are interval between neoadjuvant chemotherapy (nCRT) and surgery (24 us. 14 weeks), dentate line involvement $81 \%$ vs. $42 \%$ ), doubled number of T4 tumours (18\% vs. $9 \%$ ), minimally invasive surgery $(90 \%$ vs. $16 \%)$ and use of perineal mesh, all of them greater in ELAPE group. Surprisingly, this group presented a greater number of T0 tumours ( $9 \%$ vs. $4.5 \%$ ) and intraoperative perforations (18\% vs. $9 \%$ ), although advanced pT-stage may be considered a risk factor for specimen fragmentation, ELAPE is less likely to produce a fragmented specimen. ${ }^{14}$

Consequently, the authors were not able to demonstrate better results associated with ELAPE. And even the smaller readmission rate may be attributed to the greater number of open procedures among the historical patients. In a further analysis regarding the perineal procedures, one may note that the number of vaginal and prostate resections is not addressed; simultaneously, mesh reinforcement was inserted based on individual decisions, and $90 \%$ of ELAPE patients did so. As better results were achieved in cases without mesh insertion, it is difficult to assess how bad is the case or the mesh.

The authors also describe a smaller median length of stay after ELAPE (7 vs. 5 days). However, this finding may be interpreted as a natural consequence of a better recovery in patients undergoing a minimally invasive access, which was the preferred choice in this group.

Having all these data in mind, comparison of oncological outcomes between turns to be a difficult task. Even more thinking that ELAPE superiority over classical APR has not always been demonstrated. ${ }^{7,16-18}$

Being a young and new technical alternative, ELAPE still has to face controversies regarding nomenclature, indications, pelvic reconstruction and other important issues. The present paper brings very interesting ideas and perspectives to be discussed. More than this, it represents a local experience trying to evaluate the role and outcomes of ELAPE in the management of low rectal cancer.

\section{RE F E REN C ES}

1. Campos FG, Habr-Gama A, Nahas SC, Perez RO. Abdominoperineal excision: evolution of a centenary operation. Dis Colon Rectum. 2012;55:844-53.
2. Holm T, Ljung A, Häggmark T, Jurell G, Lagergren J. Extended abdominoperineal resection with gluteus maximus flap reconstruction of the pelvic floor for rectal cancer. $\mathrm{Br} J$ Surg. 2007;94:232-8.

3. Holm T. Controversies in abdominoperineal excision. Surg Oncol Clin N Am. 2014;23:93-111.

4. Nicholls J. No more 'standard' abdominoperineal excision. Colorectal Dis. 2013;15:1329-30.

5. Smith JJ, Garcia-Aguilar J. Advances and challenges in treatment of locally advanced rectal cancer. J Clin Oncol. 2015;33:1797-808.

6. Park EJ, Baik SH, Kang J, Hur H, Min BS, Lee KY, et al. Short-term outcomes of the modified extralevator abdominoperineal resection for low rectal cancer (with videos). Surg Endosc. 2016;30:1672-82.

7. Prytz M, Angenete E, Bock D, Haglind E. Extralevator abdominoperineal excision for low rectal cancer-extensive surgery to be used with discretion based on 3-year local recurrence results: a registry-based observational national cohort study. Ann Surg. 2016;263:516-21.

8. Shihab OC, How P, West N, George C, Patel U, Quirke P, et al Can a novel MRI staging system for low rectal cancer aid surgical planning? Dis Colon Rectum. 2011;54: 1260-4.

9. Bhoday J, Balyasnikova S, Wale A, Brown G. How should imaging direct/orient management of rectal cancer? Clin Colon Rectal Surg. 2017;30:297-312.

10. Zhang Y, Wang D, Zhu L, Wang B, Ma X, Shi B, et al. Standard versus extralevator abdominoperineal excision and oncologic outcomes for patients with distal rectal cancer: a meta-analysis. Medicine (Baltimore). 2017;96: e9150.

11. Asplund D, Haglind A, Angenete E. Outcome of extralevator abdominoperineal excision compared with standard surgery: results from a single centre. Colorectal Dis. 2012;14: 1191-6.

12. Ortiz H, Ciga MA, Armendariz P, Kreisler E, Codina-Cazador A, Gomez-Barbadillo J, et al. Multicentre propensity score-matched analysis of conventional versus extended abdominoperineal excision for low rectal cancer. Br J Surg. 2014;101:874-82.

13. Chen Y, Chi P. Meta-analysis of extralevator abdominoperineal excision for rectal cancer. Zhonghua Wei Chang Wai Ke Za Zhi. 2017;20:326-32.

14. Habr-Gama A, São Julião GP, Mattacheo A, de Campos-Lobato LF, Aleman E, Vailati BB, et al. Extralevator abdominal perineal excision versus standard abdominal perineal excision: impact on quality of the resected specimen and postoperative morbidity. World J Surg. 2017;41: 2160-7.

15. Cesar D, Araujo R, Valadão M, Linhares E, Meton F, Jesus JP. Surgical and oncological short-term outcomes of prone extralevator abdominoperineal excision for low rectal cancer. JCOL. 2018.

16. Krishna A, Rickard MJ, Keshava A, Dent OF, Chapuis PH. A comparison of published rates of resection margin involvement and intra-operative perforation between standard and 'cylindrical' abdominoperineal excision for low rectal cancer. Colorectal Dis. 2013;15: $57-65$.

17. Yang Y, Xu H, Shang Z, Chen S, Chen F, Deng Q, et al. Outcome of extralevator abdominoperineal excision over conventional abdominoperineal excision for low rectal tumor: a meta-analysis. Int J Clin Exp Med. 2015;8: 14855-62.

18. Zhou X, Sun T, Xie H, Zhang Y, Zeng H, Fu W. Extralevator abdominoperineal excision for low rectal cancer: a systematic 
review and meta-analysis of the short-term outcome.

Colorectal Dis. 2015;17:474.

Fábio Guilherme Campos ${ }^{\mathrm{a}, *}$, Carlos Augusto Real Martinez ${ }^{\mathrm{b}}$

${ }^{a}$ Faculdade de Medicina da Universidade de São Paulo, Departamento de Gastroenterologia, Divisão de Cirurgia Colorrectal, São Paulo, SP, Brazil

b Universidade Estadual de Campinas (UNICAMP), Deapartamento de Cirurgia, Divisão de Cirurgia Colorrectal, Campinas, SP, Brazil
* Corresponding author.

E-mail: fgmcampos@terra.com.br (F.G. Campos).

2237-9363/@ 2018 Published by Elsevier Editora Ltda. on behalf of Sociedade Brasileira de Coloproctologia. This is an open access article under the CC BY-NC-ND license (http:// creativecommons.org/licenses/by-nc-nd/4.0/). https://doi.org/10.1016/j.jcol.2018.10.001 